\title{
Life-style in Relation to the Risk of Breast Cancer ${ }^{\star}$
}

\author{
Keun-Young Yoo', Kazuo Tajima2, Tetsuo Kuroishi2, Kaoru Hirose2, \\ Shigeto Miura ${ }^{3}$, Hiroshi Murai ${ }^{3}$, and Minoru Yoshida ${ }^{3}$
}

1. Department of Preventive Medicine, Seoul National University College of Medicine, Seoul, Korea

2. Disivion of Epidemiology, Aichi Cancer Center Research Institute, Nagoya, Japan

3. Department of Breast Surgery, Aichi Cancer Center Hospital, Nagoya, Japan

\begin{abstract}
A hospital-based case-control analysis was conducted to assess the relationship of life-style to breast cancer in Japan. The study population was selected among the outpatients of a hospital where information on life-style had been routinely collected prior to diagnosis since 1987. The ageadjusted risk to breast cancer significantly decreased with marital status, fullterm pregnancy history, number of fullterm pregnancies, number of breastfed children, and the average length of breastfeeding, while age at first fullterm pregnancy and family history of breast cancer were positively associated with the risk. The adjusted risk, controlling for potential confoundings, significantly decreased in alcohol drinkers. On the other hand, there was a significant dose-response gradient of increasing risk with smoking. No relationship of physical activity to the disease was observed. There were significant decreases in the risk with increasing intake of rice, bean curd, soy bean paste, and green vegetables. However, no evidence of increase in the risk was found with a high fat diet. These findings suggest that further study under the specific hypothesis in a different population should be followed to confirm the different risk factors of breast cancer in Oriental people from those in the Western countries.
\end{abstract}

Alcohol, Breast neoplasms, Dietary factors, Life-style, Reproductive factors, Physical activity, Risk, Smoking

* At the time of this work, Dr. Yoo was a visiting scientist to the Department of Epidemiology, Aichi Cancer Center Research Institute, supported by the WHO Visiting Scientist Grant (ICP/PHC/014 WPRO GRANT 0004/90). 


\section{INTRODUCTION}

Life-style associated with breast cancer encompasses menstrual and reproductive factors, and personal preference, for example, smoking and drinking habits. In addition, physical activities and dietary habits are some other factors. There is an abundance of epidemiological evidence that early menarche, late menopause, and delayed age at first delivery are closely related to breast cancer ${ }^{(1,2)}$. International similarity of these factors is more persuasive to the role of estrogen ${ }^{(1,3)}$, while other factors are still controversial. An examination of related factors, which would be heterogenous among different countries, is thus necessary for a further understanding of the etiology of cancer.

This is a hospital-based case-control analysis aimed at clarifying what kind of life-style is associated with the risk of breast cancer in Japan, where the incidence of and mortality rate due to breast cancer has recently been increasing ${ }^{(4)}$.

\section{SUBJECTS}

Information on life-style has been routinely collected from all the outpatients of the Aichi Cancer Center Hospital, Nagoya, Japan, since 1987. All data was obtained prior to diagnosis, through a self-administered questionnaire under the supervision of an interviewer. The study population was primarily sampled for a study on the comparison of risk factors between breast cancer and uterine cervix cancer, the results of which will be published elsewhere. Women who were newly diagnosed as breast cancer in this hospital, both histologically and clinically, were taken as the case group from January 1,1988 to December $31,1989$. Six hundred seventy-seven controls were randomly selected among those having no evidence of any cancer in the hospital. No duplicate case, nor control, was permitted in this analysis. The cases were slightly older than the controls, but occupation and marital status did not significantly differ between the two groups (Table 1).

\section{METHODS}

All the variables on menstrual and reproductive factors, as well as variables on familial factors, were categorized in an ordinal scale. Information on both dietary habits and intake frequency was gathered through a self-administered questionnaire, in which the frequency of each item was classified in an ordinal scale with an increasing order.

For comparison with other results, relative risks of reproductive and familial factors in Table 2,3, and 4 are presented as age-adjusted risks. For other variables on life-style, potential confounding effects by age, and reproductive and familial factors, either statistically significant or biologically plausible, were controlled by the unconditional logistic model. 
Table 1 Characteristics of breast cancer cases and controls

\begin{tabular}{|c|c|c|c|c|c|}
\hline \multirow[t]{2}{*}{ Characteristics } & \multicolumn{2}{|c|}{ Cases } & \multicolumn{2}{|c|}{ Controls } & \multirow{2}{*}{$\begin{array}{l}\text { Pearson's } \\
\mathrm{x}^{2}\end{array}$} \\
\hline & No. & 8 & No. & 8 & \\
\hline Total & 522 & 100.0 & 677 & 100.0 & \\
\hline $\begin{array}{c}\text { Age in years } \\
-19 \\
20-24 \\
25-29 \\
30-34 \\
35-39 \\
40-44 \\
45-49 \\
50-54 \\
55-59 \\
60-64 \\
65-69 \\
70-74 \\
75-79 \\
80-84 \\
85-\end{array}$ & $\begin{array}{r}0 \\
1 \\
5 \\
18 \\
42 \\
76 \\
96 \\
84 \\
64 \\
63 \\
34 \\
18 \\
16 \\
3 \\
2\end{array}$ & $\begin{array}{r}0.0 \\
0.2 \\
1.0 \\
3.5 \\
8.1 \\
14.6 \\
18.4 \\
16.1 \\
12.3 \\
12.1 \\
6.5 \\
3.5 \\
3.1 \\
0.6 \\
0.4\end{array}$ & $\begin{array}{r}7 \\
21 \\
31 \\
46 \\
87 \\
141 \\
132 \\
69 \\
56 \\
36 \\
24 \\
17 \\
7 \\
2 \\
1\end{array}$ & $\begin{array}{r}1.0 \\
3.1 \\
4.6 \\
6.8 \\
12.9 \\
20.8 \\
19.5 \\
10.2 \\
8.3 \\
5.3 \\
3.6 \\
2.5 \\
1.0 \\
0.3 \\
0.2\end{array}$ & $\begin{array}{c}93.8(14) \\
p=0.00\end{array}$ \\
\hline $\begin{array}{l}\text { Occupation } \\
\text { upper } \\
\text { middle } \\
\text { lower } \\
\text { unemployed }\end{array}$ & $\begin{array}{r}239 \\
66 \\
25 \\
192\end{array}$ & $\begin{array}{r}45.8 \\
12.6 \\
4.8 \\
36.8\end{array}$ & $\begin{array}{r}320 \\
79 \\
49 \\
229\end{array}$ & $\begin{array}{r}47.3 \\
11.7 \\
7.2 \\
33.8\end{array}$ & $\begin{array}{c}3.97 \quad(3) \\
\mathrm{ns}\end{array}$ \\
\hline $\begin{array}{l}\text { Marital status } \\
\text { single } \\
\text { married }\end{array}$ & $\begin{array}{r}35 \\
481\end{array}$ & $\begin{array}{r}6.8 \\
93.2\end{array}$ & $\begin{array}{r}55 \\
617\end{array}$ & $\begin{array}{r}8.2 \\
91.8\end{array}$ & $\underset{\mathrm{ns}}{0.82}(1)$ \\
\hline
\end{tabular}

Table 2 Age-adjusted risk of breast cancer associated with reproductive factors among 1,199 Japanese women in the Aichi Cancer Center Hospital, Nagoya, Japan, during 1988-1989

\begin{tabular}{|c|c|c|}
\hline Risk factors & Categories ${ }^{11}$ & values for trend $\left.{ }^{2}\right)$ \\
\hline Marital status & single, married & $-2.5, \quad p=0.01$ \\
\hline Age at menarche & $-12,13-14,15-16$ & $0.0, \mathrm{~ns}$ \\
\hline Menstrual regularity & regular, irregular & $-1.6, p=0.10$ \\
\hline Menopausal status & pre-, postmenopause & 0.1 , ns \\
\hline $\begin{array}{l}\text { Age at natural } \\
\text { menopause }\end{array}$ & $\begin{array}{l}\text { pre- , }-44,45-49, \\
50-54,55+\end{array}$ & $0.3, \mathrm{~ns}$ \\
\hline $\begin{array}{l}\text { Fullterm pregnancy } \\
\text { history }\end{array}$ & nulli-, multiparous & $-2.8, p=0.00$ \\
\hline $\begin{array}{l}\text { Age at first }{ }^{3)} \\
\text { fullterm pregnancy }\end{array}$ & $\begin{array}{l}-19,20-24, \quad 25-29 \\
30-34,35+\end{array}$ & $4.0, p=0.00$ \\
\hline $\begin{array}{l}\text { Number of fullterm } \\
\text { pregnancies }\end{array}$ & nulli-, 1, 2, 3, 4+ & $-4.0, p=0.00$ \\
\hline \multicolumn{3}{|c|}{$\begin{array}{l}\text { Thach category was coded in increasing order. } \\
\text { 2) The chi value, instead of chi-square, was presented to show both } \\
\text { significance of the linearity and its direction. The value was drawn } \\
\text { from the change in log-likelihoods between unconditional logistic model } \\
\text { with and without the continuous variable. } \\
\text { 3esult was derived from a data restricted to multiparous group. } \\
\text { ns : p > } 0.1\end{array}$} \\
\hline
\end{tabular}


Table 3 Age-adjusted risk of breast cancer associated with breastfeeding history among 1,199 Japanese women in the Aichi Cancer Center Hospital, Nagoya, Japan, during 1988-1989

\begin{tabular}{|c|c|c|c|c|c|c|}
\hline $\begin{array}{l}\text { Risk } \\
\text { factors }\end{array}$ & Case & Control & $\begin{array}{c}\text { Adjusted } R^{1)} \\
\left(95^{\circ} \mathrm{CI}\right)\end{array}$ & $x^{2}{ }_{L R}^{2)}$ & $\mathrm{x}_{\text {trend }}^{2}{ }^{3)}$ & $\mathrm{X}_{\text {departure }}{ }^{4}$ \\
\hline \multicolumn{7}{|c|}{$\begin{array}{crrrl}\text { Number of breastfed children } & \\
0 & 133 & 146 & 1.0 & \\
1 & 79 & 92 & 0.73 & (0.48-1.10) \\
2 & 208 & 281 & 0.60 & (0.43-0.83) \\
3 & 73 & 126 & 0.41 & (0.27-0.61) \\
4+ & 29 & 31 & 0.43 & (0.23-0.80)\end{array}$} \\
\hline $\begin{array}{l}\text { Average } 1 \\
\quad 0 \\
1-3 \\
4-6 \\
7-9 \\
10-12 \\
13+\end{array}$ & $\begin{array}{l}\text { lengths } \\
133 \\
84 \\
67 \\
33 \\
171 \\
33\end{array}$ & $\begin{array}{l}\text { of brea } \\
146 \\
133 \\
117 \\
60 \\
180 \\
40\end{array}$ & $\begin{array}{l}\text { tfeeding (month) } \\
1.0 \\
0.62(0.42-0.92) \\
0.47(0.31-0.71) \\
0.44(0.26-0.74) \\
0.62(0.44-0.88) \\
0.53(0.30-0.93)\end{array}$ & $\begin{array}{r}18.4(5) \\
p=0.00\end{array}$ & $\begin{array}{l}6.8(1) \\
p=0.01\end{array}$ & $\begin{array}{r}11.6(4) \\
p=0.02\end{array}$ \\
\hline \multicolumn{7}{|c|}{ 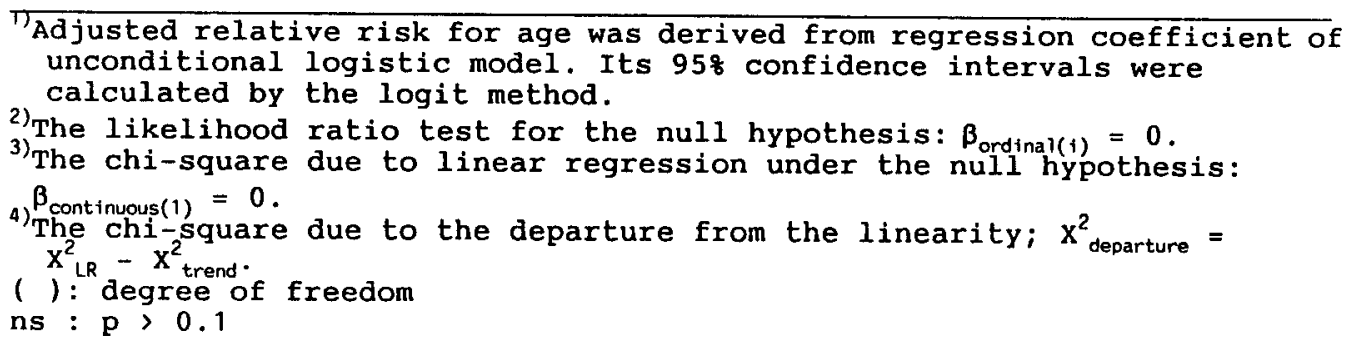 } \\
\hline
\end{tabular}

Table 4 Age-adjusted risk of breast cancer associated with familial factors among 1,199 Japanese women in the Aichi Cancer Center Hospital, Nagoya, Japan, during 1988-1989

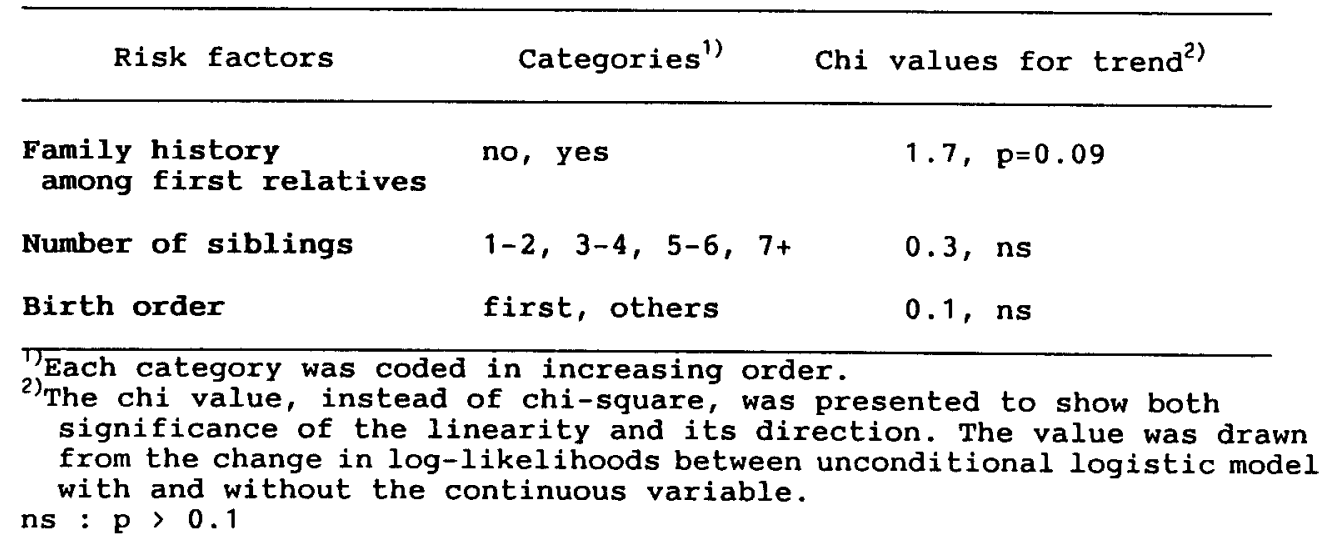

Adjusted relative risks were calculated from the logistic regression equation ${ }^{(5,6)}$. The logit method was applied for $95 \%$ confidence limits of the adjusted risk ${ }^{(7)}$. A test for the null hypothesis that the ordinal variable had no effect on the disease, as well as the test for linear trend of the logit risk in each factor was done by the likelihood ratio test ${ }^{(5,6,8)}$. The $X^{2}$ trend statistic was obtained from the change in scaled deviance; the difference in two log-likelihoods between a logistic model with and without the transformed continuous variable. For convenience, the chi-value, instead of chi-square, was presented to show implicatively both the significance of the linearity and its direction, which followed the normal distribution 
(Table 2, 4, $7 \& 8$ ). Along with the test for trend, another chi-square, $\mathrm{X}^{2}$ departure, was calculated to evaluate departure from the linearity ${ }^{(8)}$. All the statistical procedures were carried out using the PC-SAS ${ }^{(9)}$ and the GLIM system ${ }^{(10)}$. The critical level chosen for the statistical significance was 0.1 .

Table 5 Alcohol drinking, smoking habits and the risk of breast cancer among 1,199 Japanese women in the Aichi Cancer Center Hospital, Nagoya, Japan, during 1988-1989

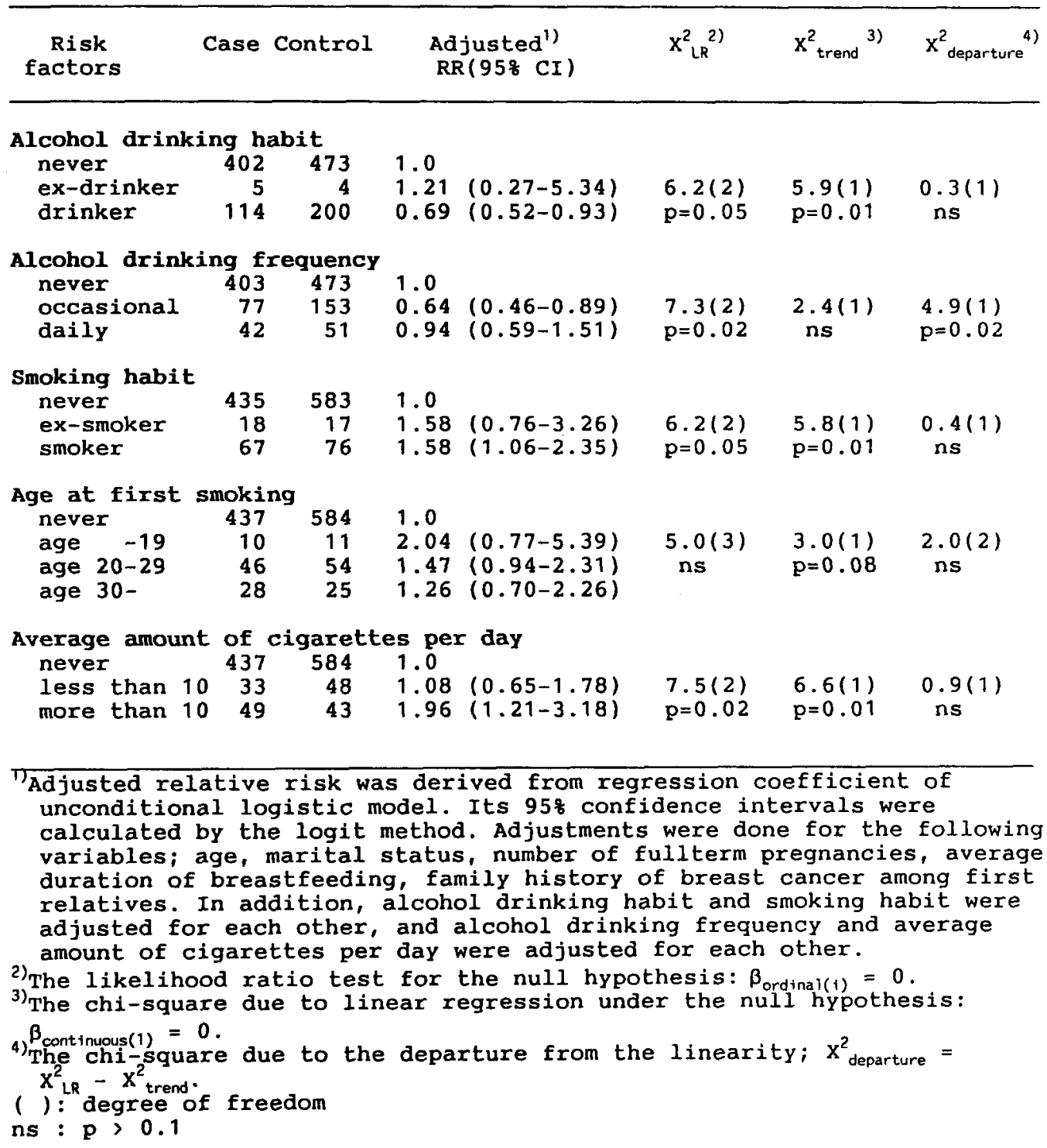


Table 6 Physical activities and the risk of breast cancer among 1,199 Japanese women in the Aichi Cancer Center Hospital, Nagoya, Japan, during 1988-1989

\begin{tabular}{|c|c|c|c|c|c|c|}
\hline $\begin{array}{c}\text { Risk } \\
\text { factors }\end{array}$ & Case & Control & $\begin{array}{l}\text { Adjusted } \\
\operatorname{RR}(95 \% \text { CI })\end{array}$ & $x_{L R}^{2}{ }^{2)}$ & $x^{2}$ trend 3$)$ & $\mathrm{x}_{\text {departure }}^{2}$ \\
\hline
\end{tabular}

sleeping time in hours

$\begin{array}{rrrrrrrr}-5 & 35 & 37 & 1.0 & & & & \\ 6-8 & 468 & 629 & 0.88 & (0.53-1.47) & 1.2(2) & 0.0(1) & 1.2(2) \\ 9- & 18 & 11 & 1.38 & (0.51-3.69) & \text { ns } & \text { ns } & \text { ns }\end{array}$

Physical activity

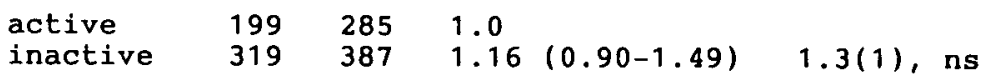

TAdjusted relative risk was derived from regression coefficient of unconditional logistic model. Its $95 \%$ confidence intervals were calculated by the logit method. Adjustments were done for the following variables; age, marital status, number of fullterm pregnancies, average duration of breastfeeding, and family history of breast cancer among first relatives.

2) The likelihood ratio test for the null hypothesis: $\beta_{\text {ordinal(i) }}=0$.

3) The chi-square due to linear regression under the null hypothesis:

4) $\beta_{\text {continuous (1) }}=0$. 4)
The chi chisuare due to the departure from the linearity; $x_{\text {departure }}^{2}=$
$x^{2}-x_{\text {trend }}$.

( ) : degree of freedom

ns : $p>0.1$

Table 7 Dietary habits and the risk of breast cancer among 1,199 Japanese women in the Aichi Cancer Center Hospital, Nagoya, Japan, during 1988-1989

\begin{tabular}{|c|c|}
\hline Risk factors & Chi values for trend ${ }^{2)}$ \\
\hline Kinds of breakfast & rice, bread, mixed, skip \\
\hline $\begin{array}{l}\text { Number of rice } \\
\text { bowl per day }\end{array}$ & half, 1-2, 3-4, 5+ \\
\hline $\begin{array}{l}\text { Hastiness in eating } \\
\text { meal }\end{array}$ & $\begin{array}{l}\text { slow, slightly slow, } \\
\text { slightly fast, fast }\end{array}$ \\
\hline $\begin{array}{l}\text { Saltiness } \\
\text { preference }\end{array}$ & $\begin{array}{l}\text { like, moderately like, }-1.5 \text {, ns } \\
\text { moderately dislike, dislike }\end{array}$ \\
\hline $\begin{array}{l}\text { Greasiness } \\
\text { preference }\end{array}$ & $\begin{array}{l}\text { like, moderately like, }-1.3 \text {, ns } \\
\text { moderately dislike, dislike }\end{array}$ \\
\hline $\begin{array}{l}\text { 2) The category was coo } \\
\text { The chi value, instea } \\
\text { fignificance of the } \\
\text { from the change in } 1 \\
\text { with and without the }\end{array}$ & $\begin{array}{l}\text { ad in increasing order. } \\
\text { linearity and its direction. The value was drawn } \\
\text { og-likelihoods between unconditional logistic model } \\
\text { continuous variable. }\end{array}$ \\
\hline
\end{tabular}


Table 8 Food intake frequency and the risk of breat cancer among 1,199 Japanese women in the Aichi Cancer Center Hospital, Nagoya, Japan, during 1988-1989

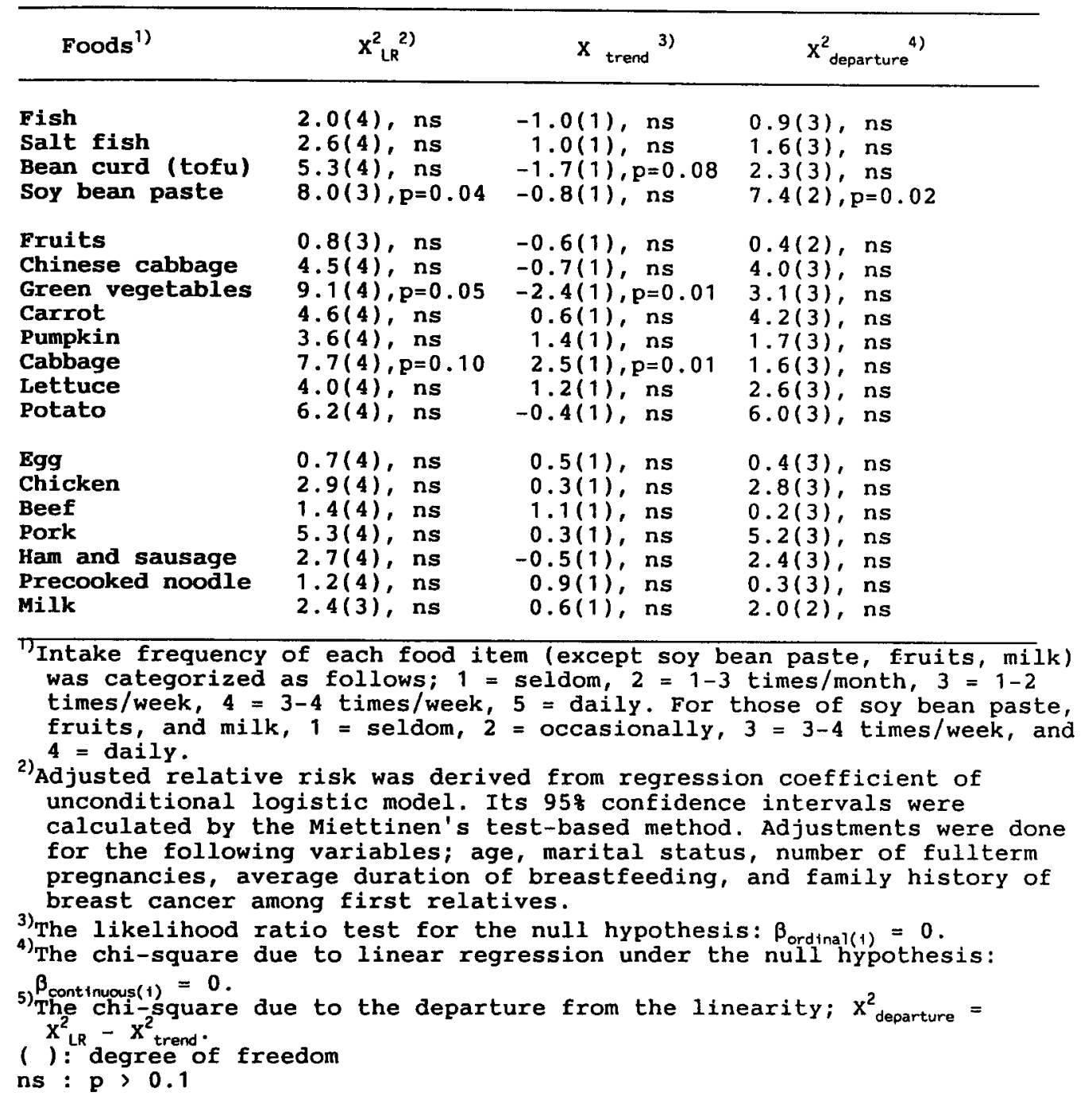

\section{RESULTS}

The age-adjusted risk of breast cancer associated with reproductive factors is summarized in Table 2. While age at menarche and natural menopause, menopausal status were not related with breast cancer, and while menstrual regularity showed borderline significance, the ageadjusted risk of breast cancer was significantly reduced with marital status, fullterm pregnancy history, number of fullterm pregnancies, number of breastfed children, and the average lengths of breastfeeding in month (Table 3). In contrast, age at first fullterm pregnancy and the family history of breast cancer among first relatives were positively associated with the risk. Neither the number of siblings nor birth order was related to the disease (Table 4). 
There was a significant decrease in the risk of breast cancer associated with alcohol (Table 5). The biggest decrease in risk was seen among drinkers (adjusted $R R=0.69,0.52-$ 0.93 ). In spite of a nonlinear relationship $\left(\mathrm{X}^{2}{ }_{\text {ceparture }}=4.9, \mathrm{df}=1, \mathrm{p}=0.02\right)$, the risk among occasional drinkers decreased significantly (adjusted $R R=0.64,0.46-0.89$ ). Contrary to alcohol, a substantial increase in the risk among ex-smokers and smokers was observed $\left(\mathrm{X}^{2}{ }_{\text {trend }}=5.8, \mathrm{df}=1, \mathrm{p}=0.01\right)$. The age at first smoking showed an inverse relationship with breast cancer. While the risk of mild smokers (less than 10 cigarettes/day) was almost similar to that of non-smokers, there was an apparent increase in the risk among smokers (more than 10 cigarettes/day) (adjusted $R R=1.96,1.21-3.18$ ), with a significant dose-dependent gradient.

A nonsignificant association between the sleeping time and the risk of breast cancer was observed. Although the risk seemed to slightly increase in physically inactive women, it was also nonsignificant (Table 6).

Among dietary habits, the intake of rice at breakfast seemed to have a protective effect against breast cancer (Table 7). This was seen from the decreasing tendency in risk with the increase in number of bowls of rice/day $\left(\mathrm{X}_{\text {trend }}^{2}=5.1, \mathrm{df}=1, \mathrm{p}=0.02\right)$. Hastiness in eating meals, or preference to saltiness or to greasiness, was not at all related to the risk of breast cancer.

The logit risk of breast cancer in Table 8 had a significant linear relationship with the intake frequency of green vegetables $(p=0.01)$, as well as of bean curd $(p=0.08)$. In spite of a nonlinear trend associated with soy bean paste $\left(\mathrm{X}_{\text {departure }}^{2}=7.4, \mathrm{df}=2, \mathrm{p}=0.02\right)$, its direction was towards protection against breast cancer. Meanwhile, the intake of cabbage showed a significant increase in the risk. There was no positive evidence on the association between the intake of food containing high calories or fat and the risk of breast cancer in this population.

\section{DISCUSSION}

Although the incidence of female breast cancer in Oriental countries is still lower than that in Western countries, it is evident that the rate is increasing in several Asian countries $^{(4,11-13)}$. Life-style associated with a disease may differ from country to country, and comparing these differences can sometimes provide important clues concerning the etiology of a disease.

Even though there was no evidence of the representativeness of study population, the authors believe that the results could be less affected by selection bias, which may arise from taking control from the outpatients in a hospital. Because the major reason of outpatients to visit this Prefectural Hospital was known to be for the diagnosis of any cancer, the patients from the Prefecture, as well as from the nearby Prefectures, having been once diagnosed in this Hospital, trended to visit other University Hospitals in the region for the treatment of the cancer. Moreover, it is a well-known fact that gathering information from patients prior to the diagnosis would be relatively free of bias due to selective recall. Any duplicate cases and controls were already sorted by their own hospital serial numbers, and removed from the study population by identification precedure using name, sex, birth year, residence, etc. Therefore there were absolutely no duplicates in both case and control group.

Age at menarche and natural menopause, menopausal status were nonsignificant variables, when their associations with breast cancer were assessed with an adjusted risk ratio for an age effect. The other variables on menstrual and reproductive behavior tumed out to be significant in this population. Referring to recent information about the etiology of breast cancer ${ }^{(3,14)}$, 
these findings were compatible with the hypothesis of the positive role of estrogen, as well as of a counterbalancing effect of progesterone in developing breast cancer. A protective effect of lactation against breast cancer was the same as the results from previous studies ${ }^{(15-17)}$. The influence of ovarian hormones, as well as hypothalamic or pituitary hormones, may have had an important role in this population.

The association of the number of siblings or birth order was not so prominent, while a positive family history of breast cancer among first relatives showed borderline significance. Although it is still unclear whether increased susceptibility is due to heritable factors and/or to common environmental exposure, an increased risk of the disease among those with a positive family history is a common finding around the world ${ }^{(1,18-20)}$.

Although drinking alcoholic beverages is one of the oldest and most widespread habits in the world, its relation to breast cancer is still not well understood. Results showed marked inconsistencies, because of difficulties in measuring and quantifying its consumption ${ }^{(1,2)}$. Unlike other papers ${ }^{(21-24)}$, this hospital-based case-control analysis showed a protective effect of alcohol against breast cancer, independent of age, reproductive factors, lactation, and even smoking. Compared to Western women, female drinkers are not as common among Orientals, least of all heavy drinkers. Further analysis, including the effect of age at first drinking, will be needed to clarify this relationship.

The relation of smoking to the risk of breast cancer is another ambiguous point. The protective effect of smoking against breast cancer or no effect on the risk was reported through several epidemiologic studies ${ }^{(21,25,26)}$. Based on the finding of an unexpectedly low risk among smokers, its has been proposed that cigarette smoking may have an anti-estrogenic effect through direct action on the ovaries or by enhanced metabolism of steroid hormones in the liver $^{(27)}$. On the other hand, several cohort studies ${ }^{(28,29)}$, as well as case-control studies ${ }^{(30,31)}$, have found increased risk of breast cancer with smoking. A deleterious effect of smoking on breast cancer was found in our study. All aspects of smoking, for example, present smoking status, age at first smoking, and amount of smoking, showed significant dose-response gradients. If it is a fact that the hospital control is more likely to be a smoker than those in the general population, our results should be biased against the null, resulting in an underestimation of the true value. Unless we were missing other important factors which need to be controlled, it is evident that smoking should increase the risk of breast cancer. Mutagenic activity has been detected in nipple aspirates of human breast fluid ${ }^{(32)}$. A direct effect of carcinogens on breast tissue seems to be plausible, but needs to be supported by further study.

Japanese women, like other Asians, have long been accustomed to a diet containing many vegetables. Even though overall dietary habits in Japan have been changing to the Western style, a preference for the traditional diet had not changed greatly among those in this population. Similar to other reports from various countries ${ }^{(13,33-35)}$, there was no evidence that a high fat diet affects the risk of breast cancer in this population. Meanwhile, green vegetables ${ }^{(36)}$, as well as the Oriental staples, rice and bean curd (tofu), showed an apparent protective effect against breast cancer. A high intake of cabbage was positively associated with the risk, which is usually prepared in Western style, like salad.

In conclusion, several menstrual and reproductive factors were confirmed as major determinants of breast cancer in Japanese women, emphasizing the role of estrogen and progesterone on the risk in this population. In addition, significant associations with breastfeeding, smoking, drinking of alcohol, and some dietary habits suggest that further study under the specific hypothesis in a different population should be followed to confirm the different risk factors of breast cancer in Oriental people from those in the Western countries. 


\section{ACKNOWLEDGEMENTS}

The authors thank Dr. Kunio Aoki, the Aichi Cancer Center, Dr. Suketami Tominaga, the Aichi Cancer Center Research Institute, for their review and advise, and to Hiroko Fujikura, Michiyo Takasaki, and Miyuki Saita for their devoted assistance in data collection and preparation.

\section{REFERENCE}

1. Petrakis, N.L., Ernster, V.L., King, M.C.: Breast, In Cancer Epidemiology and Prevention. Schottenfeld, D., Fraumeni J.F.Jr., eds., Philadelphia, London, Toronto, Mexico City, Rio de Janeiro Sydney, Tokyo, W.B. Saunders Company, p.855, 1982.

2. Kelsey, J.L., Berkowitz, G.S.: Breast cancer epidemiology. Cancer Res., 48: 5615, 1988.

3. Henderson, B.E., Ross R.K., Pike, M.C. et al.: Endogenous hormones as a major factor in human cancer. Cancer Res., 42: 3232, 1982.

4. The Bureau of Vital Statistics, Ministry of Health and Welfare: Long term trends in cancer mortality rates from 1955 to 1987 in Japan. Jpn. J. Clin. Oncol., 19: 305, 1989.

5. Breslow, N.E., Day, N.E.: Statistical methods in cancer research, In The Analysis of Case Control Studies, IARC Scientific Publications, Lyon, Vol. 1, No. 32, 1980.

6. Schlessman J.J.: Case-control studying, In Design, Conduct, Analysis, Oxford University Press, Oxford, New York, 1982.

7. Woolf, B.: On estimating the relation between blood group and disease. Ann. Human Genetics, 19: 251, 1955.

8. Holford, T.R., White, C., Kelsey, J.L.: Mutivariate analysis for matched case-control studies. Am. J. Epidemiol., 107: 245,1978.

9. SAS Institute Inc.: SAS/STAT user's guide, release 6.03 edition. Cary, SAS Institute Inc., NC, 1988.

10. The GLIM Working Party: The generalised linear interactive modelling system, release 3.77, Numerical Algorithms Group Ltd., Oxford, 1987.

11. International Agency for Research on Cancer. Cancer Incidence in Five Continents, IARC Scientific Publications, Vol.V, No.88, 1987.

12. Yu, S.Z., Lu, R.F., Xu, D.D. et al.: A case-control study of dietary and nondietary risk factors for breast cancer in Shanghai. Cancer Res., 50: 5017, 1990.

13. Yoo, K.Y., Ahn, Y.O., Park, B.J.: Changing patterns of cancer in Korea; six-year experience of cancer admissions in the beneficiaries of Korean Medical Insurance Corporation. Seoul J. Med., 29: 45, 1988.

14. Bernstein, L., Yuan, J.M., Ross, R.K., et al.: Serum hormone levels in pre-menopausal Chinese women in Shanghai and white women in Los Angeles: results from two breast cancer case-control studies. Cancer Causes and Control, 1: 51, 1990.

15. Byers, T., Graham, S., Rzepka, T. et al.: Lactation and breast cancer: evidence for a negative association in premenopausal women. Am. J. Epidemiol., 121: 664, 1985.

16. Yuan, J.M., Yu, M.C., Ross, R.K. et al.: Risk factors for breast cancer in Chinese women in Shanghai. Cancer Res., 48: 1949,1988.

17. Layde, P.M., Webster, L.A., Baughman, A.L. et al.: The independent associations of parity, age at first full term pregnancy, and duration of breastfeeding with the risk of breast cancer. J. Clin. Epidemol., 42: 963, 1989.

18. Claus, E.B., Risch, N.J., Thompson, W.D.: Age at onset as an indicator of familial risk of breast cancer. Am J. Epidemiol., 131: 961, 1990. 
19. Mettlin, C., Corghan, I., Natarajan, N. et al.: The association of age and familial risk in a case-control study of breast cancer. Am. J. Epideimol., 131: 973, 1990.

20. Ogawa, H., Tominaga, S., Kato, I.: Familial clustering of cancer: Analysis of cancer registry data. In Genetics of Human Tumors in Japan, ed., Japanese Cancer Associaton, Japan Scientific Society Press, Tokyo, p.135, 1988.

21. O'Connell, D.L., Hulka, B.S., Chambless, L.E. et al.: Cigarette smoking, alcohol consumption, and breast cancer risk. J. Natl. Cancer Inst., 78: 229, 1987.

22. Willett, W.C., Stampfer, M.J., Colditz, G.A. et al.: Moderate alcohol consumption and the risk of breast cancer. N. Engl. J. Med., 316: 1174, 1987.

23. Kato, I., Tominaga, S., Terao, C.: Alcohol consumption and cancers of hormones-related organs in females. Jpn. J. Clin. Oncol., 19: 202, 1989.

24. Schatzkin, A., Carter, C.L., Green, S.B. et al.: Is alcohol consumption related to breast cancer? Results from the Framingham Heart Study. J. Natl. Cancer Inst., 81: 31, 1989.

25. Baron, J.A., Byers, T., Greenberg, E.R. et al.: Cigarette smoking in women with cancers of the breast and reproductive organs. J. Natl. Cancer Inst., 77:677, 1986.

26. Ewertz, M.: Smoking and breast cancer risk in Denmark. Cancer Causes and Control, 1: 31, 1990.

27. Baron, J.A.: Smoking and estrogen-related disease. Am. J. Epidemiol., 119: 9, 1984.

28. Hiatt, R.A., Fireman, B.H.: Smoking, menopause, and breast cancer. J. Natl. Cancer Institute, 76: 833, 1986.

29. Lund, E.: Smoking and estrogen-related disease. Am. J. Epidemiol., 121: 324, 1985.

30. Schechter, M.T., Miller, A.B., Howe, G.R.: Cigarette smoking and breast cancer: a casecontrol study of screening program participants. Am. J. Epidemiol., 121: 479, 1985.

31. Horn, P.L., Thompson, W.D.: Risk of contralateral breast cancer: associations with factors related to initial breast cancer. Am. J. Epidemiol., 128: 309, 1988.

32. Petrakis, N.L., Maack, C.A., Lee, R.E. et al.: Mutagenic activity in nipple aspirators of human breast fluid. Cancer Res., 40: 188,1980.

33. Hirohata, T., Shigematsu, T., Nomura, A.M.Y. et al.: Occurrence of 'breast cancer in relation to diet and reproductive history: a case-control study in Fukuoka, Japan. Natl. Cancer Inst. Monogr., 69: 187, 1985.

34. Katyouyanni, K., Trichopoulos, D., Boyle, P. et al.: Diet and breast cancer: a case-control study in Greece. Int. J. Cancer, 38: 815, 1986.

35. Willett, W.C., Stampfer, M.J., Colditz, G.A. et al.: Dietary fat and the risk of breast cancer. N. Engl. J. Med., 316: 22, 1987.

36. Hirayama, T.: A large scale cohort study on cancer risks by diet-with special reference to the risk reducing effects of green-yellow vegetable consumption. In Diet, Nutrition and Cancer, eds, Hayashi, T. et al., Japan Sci. Soc. Press, Tokyo, p.41, 1986. 